\title{
NIAT ADOPSI TEKNOLOGI INFORMASI: SEBUAH KAJIAN EMPIRIS ONLINE BUSINESS
}

\author{
Haryanto \\ ayahromo@gmail.com \\ Program Studi Manajemen Fakultas Ekonomi and Bisnis UNS Surakarta
}

\begin{abstract}
The objective of this study is to examine the relationships of variables of Technology Acceptance Model and Theory of Planned Behavior, i.e. perceived easy of use, perceived usefulness, attitude, subjective norm, perceived behavioral control, and intention. Setting of this study is students conducting online business. Respondents of this research were students of Universitas Sebelas Maret that have intention to re-use internet to do their business. Based on purposive sampling method, there were 161 participants in this research completing questioner that have passed validity and reliability test. In order to test the hypotheses that have been formulated, SEM GeSCA was applied. According to output of GeSCA, the value of FIT, AFIT, and GFI are $60.1 \%, 59.5 \%$, and 0.989 respectively. That means the research model is fit. Furthermore, there are five hypotheses not be rejected include perceived easy to use influences perceived usefulness; perceived usefulness effects to attitude; attitude and perceived behavioral control impact to intention. Meanwhile, the hypotheses around the effect of perceived easy to use to attitude and subjective norm to intention are rejected.
\end{abstract}

Keywords: technology acceptance model, theory of planned behavior, entrepreneurships, online business

\begin{abstract}
ABSTRAK
Penelitian ini menguji hubungan antara variabel dalam Technology Acceptance Model, yang meliputi variabel perceived easy to use, perceived usefulness, sikap, dan niat dengan Theory of Planned Behavior yang mencakup sikap, subjective norm, dan perceived behavioral control. Setting penelitian adalah mahasiswa yang melakukan online business. Pengujian instrumen berdasarkan confirmatory factor analysis untuk pengujian validitas dan cronbach alpha untuk pengujian reliabilitas. Berdasarkan purposive sampling method, terdapat 161 responden yang berpartisipasi dalam penelitian ini. Selanjutnya, pengujian hipotesis menggunakan analisis SEM-GeSCA. Hasil pengujian mengindikasikan bahwa model penelitian fit karena nilai FIT, AFIT, dan GFI berturut-turut sebagai berikut 60,1\%; 59,5\%;0,989. Oleh karena itu, pengujian hipotesis bisa dilakukan. Terdapat lima hipotesis yang didukung, yakni pengaruh perceived easy to use terhadap perceived usefulness; pengaruh perceived usefulness terhadap sikap dan juga terhadap niat; pengaruh sikap terhadap niat; dan pengaruh perceived behavioral control terhadap niat. Namun hipotesis tentang pengaruh perceived easy to use terhadap sikap dan pengaruh subjective norm terhadap niat tidak didukung.
\end{abstract}

Kata kunci: technology acceptance model; theory of planned behavior; wirausaha; online business

\section{PENDAHULUAN}

Badan Pusat Statistik (BPS) melalui Survei Sosial Ekonomi Nasional (Susenas) pada bulan Maret 2006 menyebutkan bahwa jumlah penduduk miskin di Indonesia sebesar 39,05 juta atau 17,75 persen dari total 222 juta penduduk. Penduduk miskin bertambah empat juta orang dibanding yang tercatat pada Februari 2005. Data tentang pengangguran berada pada kisaran 10,8\%-11\% dari tenaga kerja yang masuk kategori sebagai pengangguran terbuka. Situasi tersebut menunjukkan bahwa masalah pengangguran termasuk yang berpendidikan tinggi akan berdampak negatif terhadap stabilitas sosial kemasyarakatan 
(www. kelembagaan.dikti.go.id, 2009).

Kenyataan di lapangan, sebagian besar lulusan perguruan tinggi adalah kategori pencari kerja bukan pencipta kerja. Hal ini mengindikasi bahwa aktivitas kewirausahaan (Entrepreneurial Activity) yang relatif masih rendah. Entrepreneurial Activity diterjemahkan sebagai individu aktif dalam memulai bisnis baru dan dinyatakan dalam persen total penduduk aktif bekerja. Semakin tinggi indek Entrepreneurial Activity maka semakin tinggi level entrepreneurship suatu negara (Boulton dan Turner, 2005 dalam www.kelembagaan.dikti.go.id,2009).

Salah satu pilar dalam pembentukan softskill wirausaha adalah kemampuan untuk bertindak efisien dengan tidak melupakan penciptaan nilai tambah untuk kemakmuran. Usaha pencapaian kondisi tersebut bisa dilakukan dengan berbagai metode, satu diantaranya adalah maksimalisasi teknologi informasi. Aplikasi teknologi informasi di bidang bisnis, seperti $e$ commerce, berdampak luas, yakni terbukanya akses ke hulu dan hilir, terbukanya akses ke supplier dan konsumen. Salah satu trend aplikasi teknologi informasi di bidang bisnis yang memberi manfaat yang besar adalah e-commerce. Oleh karena itu, pengembangan kewirausahaan perlu juga memperhatikan sisi intangible, yakni penguasaan softskill melalui adopsi $e$-commerce.

Secara teoritis, model yang berpengaruh langsung terhadap adopsi teknologi adalah Technology Acceptance Model-TAM(Davis, 1989). Pengembangan model tersebut diikuti dengan penggunaan model dari Davis dengan dua variabel utama yaitu usefullness dan ease of use sebagai variabel utama dalam TAM (Davis, 1986). Variabel usefullness merujuk pada situasi dimana konsumen menyadari manfaat dari penggunaan suatu teknologi, sedangkan variabel easy of use merupakan kesadaran bahwa teknologi tersebut dapat konsumen aplikasikan tanpa mengalami banyak hambatan. Kedua variabel ini berada dalam ranah kognitif.
Kajian menunjukkan bahwa aplikasi TAM banyak dilakukan pada situasi yang bersifat mandatory (Templeton and Byrd, 2003). Sifat mandatory menunjukkan bahwa adopsi teknologi merupakan kewenangan atasan dalam struktur organisasi formal. Kondisi tersebut menyiratkan bahwa individu dalam organisasi melakukan tindakan berdasarkan instruksi bukan merupakan kebutuhan yang muncul dari kesadaran. Pada sisi lain, perilaku individu yang didasari kesadaran akan sangat mungkin berbeda dampaknya dengan yang didasari kewajiban. Oleh karena itu, kajian aplikasi TAM dalam setting yang nonmandatory menjadi menarik untuk dilakukan.

Model kedua adalah theory of planned behavior-TPB- (Ajzen, 1991) tentang faktorfaktor yang mempengaruhi perilaku niat, yang terbentuk melalui attitude toward the behavior, subjective norm, dan perceived behavioral controll. Hasil penelitian ini menunjukkan bahwa antecedent niat seseorang dalam bertindak dibentuk oleh ketiga variabel tersebut, yakni attitude towards the bahavior, subjective norm, dan perceived behavioral controll. Pada saat yang bersamaan intention itu sendiri merupakan antecedent dari behavior (Ajzen, 1991).

Atttitude toward the behavior menunjukkan evaluasi terhadap perilaku yang bisa bersifat positif maupun negatif, subjective norm merupakan pengaruh sosial yang diterima individu yang berdampak pada perilaku bertindak atau tidak bertindak, sedangkan perceived behavioral controll adalah kemudahan atau kesulitan untuk bertindak dan kemungkinan berdampak langsung atau tidak langsung terhadap perilaku itu sendiri (Blanchard et al., 2003)

Tujuan penelitian ini adalah menganalisis hubungan antara variabel dalam TAM dan TPB dalam setting online business. Kedua pendekatan tersebut mengacu pada niat untuk bertindak sebagai pembentuk variabel bertindak (behavioral). Penelitian ini menarik dilakukan karena selama ini aplikasi TAM lebih banyak dilakukan pada kondisi mandatory (Davis, Bagozzi, and 
Warshaw, 1989; Templeton and Byrd, 2003), sedangkan pada studi ini aplikasi TAM bersifat kerelaan atau nonmandatory. Kedua, penelitian ini juga menganalisis TPB yakni menguji variabel subjective norm dan perceived behavioral sebagai variabel yang diduga berpengaruh dalam niat adopsi online business. Ketiga, setting studi pada mahasiswa yang memiliki bisnis online, setting penelitian ini belum banyak dianalisis.

\section{TINJAUAN TEORETIS}

TAM merupakan pendekatan yang sering dilakukan untuk memahami perilaku individu dalam adopsi teknologi. Variabel TAM meliputi perceived easy to use, perceived usefulness, sikap, dan niat (Davis, 1989). Sedangkan, TPB meliputi variabel sikap, subjective norm, perceived behavioral control, dan niat (Ajzen, 1991). Kedua pendekatan tersebut memiliki irisan yang kuat dalam hal sikap dan niat. Oleh karena itu, penelitian ini membangun konstruksi berdasarkan kekuatan irisan kedua model.

\section{Technology Acceptance Model (TAM)}

Adopsi teknologi merupakan ranah yang menjadi hal menarik saat ini seiring dengan perkembangan teknologi informasi. Kehidupan sehari-hari tidak bisa lepas pada ketergantungan teknologi informasi, oleh karena itu memahami perilaku individu dalam adopsi teknologi menjadi kajian yang banyak dilakukan. TAM dikembangkan untuk mampu memotret motivasi individu dalam adopsi teknologi (Davis, 1989). Dasar utama TAM adalah bahwa setiap individu memiliki motivasi yang bisa dijelaskan berkaitan dengan sikap terhadap adopsi teknologi (Chuttur, 2009).

Terdapat dua variabel utama yang mempengaruhi sikap dan niat adopsi teknologi, yakni perceived easy of use (PEU) dan perveived usefulness (PU) (Davis, 1993; 1989; Davis et al., 1989; Yusoff and Muhammad, 2009). Perceived easy to use merupakan persepsi kemudahan sebuah sistem. Menurut Davis et al. (1989) percei- ved easy to use adalah tingkat keyakinan seseorang bahwa dalam menggunakan suatu sistem akan terbebas dari usaha. Teknologi yang mempunyai perintahperintah yang mudah ditemukan dan mudah dimengerti akan mempengaruhi persepsi seseorang bahwa teknologi tersebut mudah digunakan. Sistem informasi yang dipersepsikan lebih mudah oleh pengguna dan mempunyai kompleksitas yang lebih sedikit akan memiliki kemungkinan yang lebih tinggi untuk diadopsi dan digunakan.

Sedangkan perceived usefulness (PU) merujuk pada kemanfaatan yang diterima ketika mengadopsi sistem tersebut. Secara spesifik perceived usefulness adalah tingkat kepercayaan seseorang bahwa suatu teknologi yang digunakan akan mampu meningkatkan kinerjanya (Davis et al., 1989). Pengertian ini menunjukkan bahwa persepsi kemanfaatan merupakan sebuah ukuran dari kesulitan atau usaha yang berat pada akhirnya akan menimbulkan perhatian untuk menggunakan suatu teknologi. Perceived usefulness merupakan sebuah ukuran dari suatu harapan atas penggunaan suatu sistem. Perceived usefulness juga dapat diartikan sebagai besarnya persepsi konsumen mengenai kegunaan teknologi atau sistem informasi.

Berdasarkan TAM, perceived easy to use dan perceived usefulness berpengaruh terhadap sikap individu dalam adopsi teknologi. Sikap merupakan tendensi psikologis yang diekpresikan melalui derajad yang mana seseorang melakukan evaluasi yang bersifat favorable atau unfavorabel atas perilakunya (Fishbein and Ajzen, 1974; 1981; Ajzen, 1991). Ajzen (1991) menyatakan bahwa perasaan favorable atau unfavorable dikaitkan dengan penerimaan seseorang terhadap stimulus dari suatu objek yang dinilainya. Penilaian individu dalam hal ini terkait kuat pengalaman individu bersangkutan. Jadi, respon individu, baik positif maupun negatif, dipengaruhi oleh stimulus yang diterima. Bila stimulus yang diterima dirasakan sebagai sesuatu yang 
baik atau sesuai dengan harapan maka akan menimbulkan sikap positif terhadap stimulus tersebut, begitu pula sebaliknya.

Lebih lanjut TAM menyatakan bahwa sikap yang terbentuk memiliki pengaruh yang positif terhadap niat bertindak atau niat mengadopsi teknologi. Niat merupakan indikator motivasi individu dalam bertindak, niat menunjukkan seberapa keras seseorang mencoba dan seberapa banyak usaha yang dilakukan untuk bisa bertindak (Ajzen, 1991). Sejalan dengan definisi tersebut maka niat merupakan proxy yang paling kuat bagi pengukuran perilaku atau variabel bertindak.

\section{Theory of Planned Behavior (TPB)}

Teori ini menyatakan bahwa perilaku seseorang bisa diprediksi berdasarkan niat, sedangkan niat dipengaruhi oleh sikap, subjective norm, dan perceived behavioral control. Pendekatan ini merupakan backbone dari TAM yang dikembangkan oleh Davis (Chuttur, 2009).

Subjective norms adalah sebuah fungsi dari satu set belief yang dipengaruhi oleh individu-individu utama disekitar seseorang, seperti orangtua, suami atau istri, teman dan sebagianya (Fishbein and Ajzen, 1974). Peran individu tersebut seringkali menyatakan "persetujuan atau tidak persetujuan" terhadap perilaku orang yang bersangkutan. Subjective norms dalam model TPB fokus pada seberapa besar orangorang disekeliling mempengaruhi keputusan seorang individu.

Perceived behavioral control merujuk pada kontrol mengenai kemampuan diri. Oleh karena itu perceived behavioral control didefinisikan sebagai perilaku seseorang yang dipengaruhi oleh keyakinan terhadap kemampuan yang dimilikinya untuk bertindak (Ajzen, 1991). Hal ini mengindikasi bahwa motivasi intrinsik memiliki peranan besar dalam mendasari tindakan individu.

\section{Hipotesis}

Hasil penelitian terdahulu menunjukkan bahwa perceived easy to use berpengaruh terhadap perceived usefulness. Semakin mudah sebuah sistem teknologi maka berdampak terhadap kemanfaatan yang diterima dari adopsi teknologi tersebut. Lebih lanjut, variabel perceived easy to use dan perceived usefulness memiliki pengaruh terhadap terbentuknya sikap individu dalam adopsi teknologi. Hal ini didukung oleh hasil penelitian Davis et al. (1989); Davis (1989); Cowen (2009); Yusoff and Muhammad (2009); Shen Demei, Laffey James, Lin Yinmei (2006). Oleh karena itu, dirumuskan hipotesis sebagai berikut:

$\mathrm{H}_{1}$ : Perceived easy to use (PEU) mempengaruhi perceived usefulness (PU).

$\mathrm{H}_{2}$ : Perceived easy to use (PEU berpengaruh terhadap sikap.

$\mathrm{H}_{3}$ : Perceived usefulness (PU) berpengaruh terhadap sikap.

Penelitian Ajzen (1991); Fishbein and Ajzen (1974; 1981); Vallerand et al. (1992) menyatakan bahwa niat dipengaruhi oleh sikap, subjective norm, dan perceived behavioral control. Hal ini mengindikasi bahwa niat individu untuk melakukan suatu tindakan dipengaruhi oleh variabel sikap, subjective norm, dan perceived behavioral control. Ketiga variabel tersebut memiliki peranan yang vital dalam pembentukan niat yang merupakan proxy kuat atas perilaku atau keputusan bertindak individu.

Selain itu, hasil penelitian Davis (1993; 1989); Davis et al. (1989); Almahamid, Mcadams, Kalaldeh, and Eed, (2010) menyatakan bahwa perceived usefulness berpengaruh positif dan signifikan terhadap niat adopsi teknologi. Hasil kajian tersebut menunjukkan bahwa semakin besar manfaat yang dirasakan individu dalam adopsi teknologi, semakin kuat juga niat untuk mengadopsi teknologi terkait. Berdasarkan penelitian-penelitian tersebut, maka dirumuskan hipotesis sebagai berikut:

$\mathrm{H}_{4}$ : Sikap berpengaruh positif terhadap niat

$\mathrm{H}_{5}$ : Subjective norms berpengaruh positif terhadap niat

$\mathrm{H}_{6}$ : Perceived behavioral control berpengaruh positif terhadap niat 
$\mathrm{H}_{7}$ : Perceived usefulness mempengaruhi niat

\section{Model Penelitian}

TAM dan TPB merupakan dua pendekatan tentang analisis keperilakuan. TAM berfokus pada perilalku individu dalam adopsi teknologi, yang dikembangkan atas variabel perceived easy to use, perceived usefulness, sikap, dan niat (Davis, 1989). Variabel perceived easy to use dan perceived usefulness merupakan anteseden variavel sikap. Selanjutnya variabel niat adopsi dipengaruhi secara langsung oleh variabel perceived usefulness dan variabel sikap.

TPB merupakan model yang berfokus pada analisis perilaku inidividu dalam ber tindak. Perilaku individu dalam bertindak dipengaruhi secara langsung oleh niat untuk bertindak, sedangkan niat dipengaruhi oleh sikap, subjective norm, dan perceived behavioral control (Ajzen, 1991).

Berdasarkan kedua pendekatan tersebut, maka model penelitian ini dikonstruksi. Berikut adalah model dalam penelitian ini:

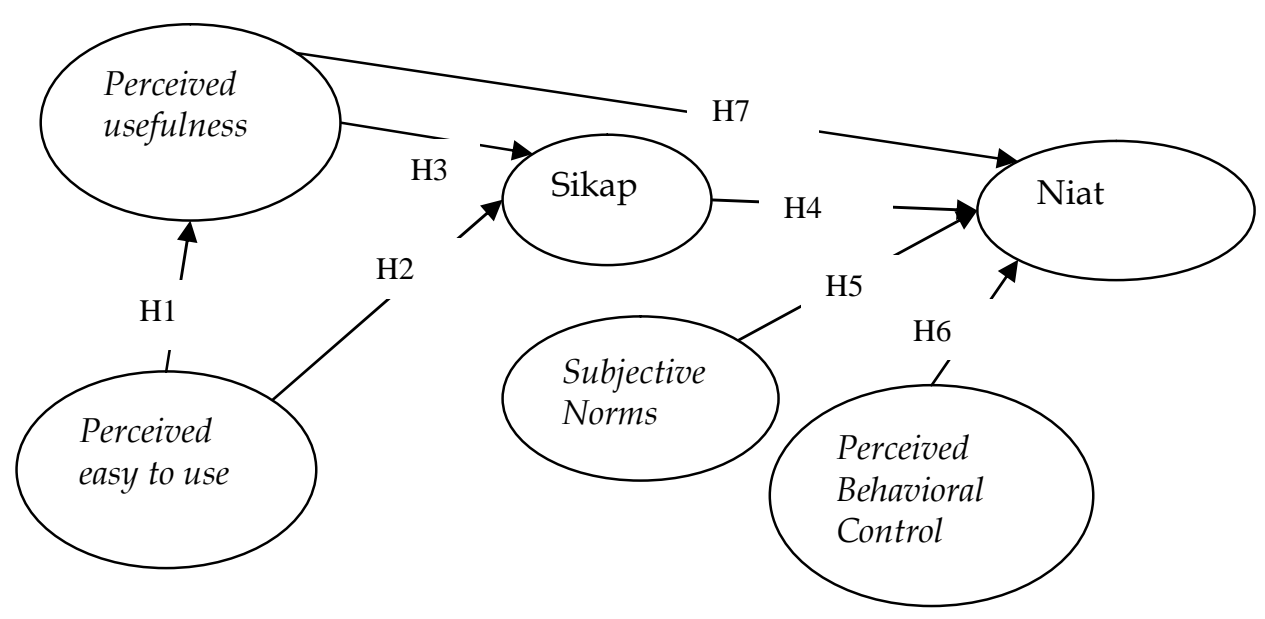

Gambar 1

Sumber: Konstruksian peneliti, 2014

Model Penelitian

\section{METODE PENELITIAN}

Pengumpulan data untuk pengujian hipotesis yang dikonstruksikan menggunakan kuesioner. Oleh karena itu data penelitian ini termasuk ketegori data primer. Kuesioner penelitian ini sudah melewati pengujian instrumen, sehingga layak dipergunakan dalam pengumpulan data. Lebih lanjut dilakukan pengujian model melalui measurement of fit model, bila model fit maka tahap berikutnya, yakni pengujian hipotesis dilakukan.

\section{Populasi dan Sampel}

Responden penelitian merupakan mahasiswa UNS yang pernah melakukan dan berniat untuk kembali berbisnis secara online. Responden diambil dari populasi penelitian yakni mahasiswa UNS yang pernah berbisnis secara online. Populasi tersebut memiliki anggota, namun tidak bisa dipastikan besaran jumlahnya. Oleh karena itu penelitian ini menggunakan nonprability sampling method (Sekaran, 1992; Crask, Fox, and Stout, 1995; Aaker, Kumar, and Day, 2000) dengan teknik pengambilan sampel berdasarkan purposive sampling, yakni dengan penetapan kriteria anggota populasi yang berniat kembali untuk melakukan bisnis online. Data diperoleh melalui isian kuesioner oleh partisipan penelitian. Key statement dalam kuesioner harus diisi partisipan untuk memastikan bahwa responden memenuhi kriteria yang 
telah ditetapkan sehingga tujuan penelitian terpenuhi.

\section{Pengujian Instrumen Penelitian}

Kuesioner sebagai instrumen penelitian diadopsi dari penelitian terdahulu (Fishbein and Ajzen, 1974; Davis, 1989; 1993; Vallerand et al., 1992; Venkatesh, 2000) yang disesuaikan dengan kondisi setting penelitian. Skala pengukuran dalam kuesioner adalah skala interval dengan pendekatan Likert 5 points, yakni 1 (sangat tidak setuju) sampai dengan 5 (sangat setuju) (Sekaran, 1992).

Uji instrumen meliputi uji validitas yang dilakukan untuk memastikan bahwa item pernyataan kuesioner mengukur variabel yang seharusnya diukur, dan uji reliabilitas untuk menguji konsistensi item pernyataan. Pengujian dilakukan dengan confirmatory factor analysis (CFA) untuk uji validitas dan cronbach alpha untuk uji reliabilitas.

Pengujian validitas dalam penelitian ini melalui tahapan pengujian sampel kecil dan sampel besar. Pengujian validitas sampel kecil bertujuan untuk memastikan bahwa instrumen penelitian layak dalam hal validitas dan reliabilitas sebagai sumber pengumpulan data. Tahapan sampel kecil dilakukan terhadap sampel sebesar 60 responden.

Hasil pengujian validitas dengan confirmatory factor analisis menunjukkan bahwa beberapa item kuesioner nilainya kurang dari 0.4 dan juga ada beberapa yang overloading. Oleh karena itu, dilakukan telaah lebih lanjut terhadap pilihan kata. Hasil telaah menunjukkan pilihan kata tidak ada masalah, misal ambigu. Akhirnya dilakukan proses trial error dengan cara melakukan dropping item yang bermasalah. Terdapat 12 item yang harus didrop dan tidak diikutkan dalam proses berikutnya. Item tersebut meliputi variabel perceived easy of use (peou1, peou2), perceived usefulness (pu1, pu2, pu3, pu4), perceived behavioral control (pbc1, pbc2, pbc3, pbc4, pbc5), dan subjective norm (sni1). Proses dropping item dilakukan tanpa mengurangi kemampuan item kuesioner dalam mengukur variabel.

Instrumen yang lolos dalam pengujian sampel kecil selanjutnya dipergunakan untuk pengumpulan data. Sebanyak 161 responden berpartisipasi dalam penelitian ini. Sebelum analisis lanjut, dilakukan uji validitas kembali dengan sampel sebanyak 160. Hasil pengujian validitas menunjukkan bahwa item kuesioner mampu mengukur variabel yang seharusnya diukur. Loading factor setiap indikator instrument penelitian diatas rule of thumb, yakni 0,4 dan juga tidak ada indikator yang mengalami overloading. Hasil ini menunjukkan bahwa instrument penelitian memenuhi kaidah validitas yang dipersyaratkan. Setiap item mengukur variabel yang seharusnya diukur berdasarkan pengkelompokkan loading factor item pada kolom factor.

Besaran nilai loading berkisar pada angka 0,7. Angka tersebut menunjukkan bahwa indikator instrumen penelitian ini memiliki kekuatan yang baik dalam mengukur variabel. Hal ini sesuai kaidah besaran loading yang menyatakan bahwa semakin besar nilai loading maka semakin kuat indikator tersebut dalam mengukur variabel. Lihat apendiks C.

Selanjutnya, instrumen penelitian juga harus lolos pengujian reliabilitas. Uji reliabilitas bertujuan untuk memastikan bahwa instrumen penelitian memiliki konsistensi dan stabilitas dalam mengukur konsep dan mampu menilai "goodness" dari alat ukur (Sekaran, 1992). Cronbach Alpha dipergunakan sebagai pengujian reliabilitas dengan cut off nilai alpha lebih dari atau sama dengan 0,6 (Sekaran, 1992).

Hasil pengujian reliabilitas dengan software SPSS 16 menghasilkan nilai cronbach alpha lebih besar dari 0,6. Hal tersebut membuktikan bahwa seluruh variabel penelitian lolos uji reliabilitas. Secara berturutturut, hasil uji reliabilitas adalah 0,920 (perceived easy to use); 0,780 (perceived usefulness); 0,926 (attitude/sikap); 0,720 (subjective norms); 0,652 (perceived behavioral control); 0,895 (intention to use/niat). Lihat Apendiks 
D. Jadi, secara keseluruhan instrumen penelitian ini tidak menghadapi kendala untuk pengumpulan data. Instrumen mampu dipergunakan dalam pengumpulan data, sehingga data yang dianalisis lebih lanjut secara kaidah statistik tidak bermasalah.

\section{Measures of Fit Model}

Analisis SEM-GeSCA mensyaratkan bahwa model yang dikonstruksi fit bila memenuhi salah satu unsur dari GFI atau SRMR. Sedangkan nilai FIT dan AFIT dalam GeSCA sepadan dengan nilai $\mathrm{R}^{2}$ dan adjusted $R^{2}$ dalam analisis regresi. Tabel 1 merupakan hasil measures of fit model studi ini.

\begin{tabular}{lcc}
\multicolumn{2}{c}{ Tabel 1 } \\
\multicolumn{2}{c}{ Measures of Fit Model } \\
\hline \hline Indikator & Skor \\
\hline FIT & 0,601 \\
AFIT & 0,595 \\
GFI & 0,989 \\
SRMR & 0,157 \\
NPAR & 51 \\
\hline
\end{tabular}

Skor FIT dan AFIT berturut-turut $60,1 \%$ dan 59,5\% mengindikasi bahwa variabel perceived easy to use, perceived usefulness, sikap, subjective norm, perceived behavioral control, dan niat mampu menjelaskan model 59,5\% sedangkan 39,5\% dijelaskan oleh variabel yang tidak diamati dalam studi ini. GFI 0,989 diatas cut-off yang disyaratakan yakni 0,900, skor ini menunjukkan bahwa model yang diteliti memiliki level fit yang tinggi, artinya model fit. Sedangkan nilai SRMR yang disyaratkan sebesar kurang dari atau sama dengan 0,08 tidak terpenuhi. Namun, model dalam studi ini tetap dikategorikan fit (Hwang and Park, 2014).

\section{ANALISIS DAN PEMBAHASAN Profile Responden}

Partisipan studi ini adalah mahasiswa yang memiliki online business dan berniat untuk menggunakan kembali. Profile responden meliputi kategori jenis kelamin, lama waktu telah melakukan bisnis secara online, dan jumlah transaksi rata-rata setiap bulan. Detail responden ditampilkan di tabel 2.

Sumber: Data primer diolah, 2014

Tabel 2

Profile Responden

\begin{tabular}{lcc}
\hline \hline Kategori & Jumlah & Persentase (\%) \\
\hline Jenis Kelamin & & \\
$\quad$ Pria & 93 & $58 \%$ \\
$\quad$ Wanita & 68 & $42 \%$ \\
Lama Berbisnis online & & \\
$\quad>=2$ tahun & 47 & $29 \%$ \\
$\quad<\quad 2$ tahun & 114 & $71 \%$ \\
Frekuensi transaksi / bulan & & \\
$\quad>=3$ & 138 & $86 \%$ \\
$\quad<3$ & 23 & $14 \%$ \\
\hline Sumber: Data primer diolah, 2014 & &
\end{tabular}

Mayoritas responden penelitian ini adalah pria dengan lama berbisnis kurang dari 2 tahun dan besaran frekuensi transaksi lebih dari 3 kali dalam sebulan. Ber- dasarkan jenis kelamin, walaupun mayoritas pria namun selisih antara pria dan wanita tidak berbeda jauh. Hal ini mengindikasi bahwa relatif tidak ada perbedaan 
jenis kelamin dalam menekuni bisnis online. Hal berbeda tampak dalam hal lama berbisnis, mayoritas responden mulai melakukan bisnis online belum lebih dari 2 tahun. Namun, walaupun lama berbisnis sebagian besar kurang dari 2 tahun tapi mayoritas melakukan transaksi lebih dari 3 kali dalam sebulan. Hasil ini membuktikan bahwa partisipan penelitian ini memiliki pemahaman yang baik dalam sistem online business.

\section{Pengujian Hipotesis}

Pengujian hipotesis menggunakan software SEM GeSCA (Generalized Structured Component Analysis) yang dikembangkan oleh Hwang and Park (2014). Analisis GeSCA diklaim lebih powerful dibandingkan analisis SEM yang lain dengan pertimbangan fasilitas bootstrap memungkinkan diabaikannya asumsi kecukupan sampel dan normalitas data, selain itu kemampuan untuk menganalisis model yang bersifat reflektif maupun formatif (Solimun, 2013).
Berdasarkan analisis SEM-GeSCA, terdapat lima hipotesis yang didukung dan dua hipotesis yang ditolak. Analisis berdasarkan nilai CR dengan level signifikansi $5 \%$, yakni lebih dari atau sama dengan 1,96. Secara rinci ditampilakan di Tabel 3 dan Gambar 2.

Tabel 3

Path Coefficients

\begin{tabular}{|c|c|c|c|}
\hline $\begin{array}{c}\text { Hubungan } \\
\text { Variabel }\end{array}$ & Estimastes & $S E$ & $C R$ \\
\hline PU->A & 0.348 & 0.076 & $4.57^{\star}$ \\
\hline PU->ITU & 0.250 & 0.083 & $3.0^{*}$ \\
\hline A->ITU & 0.161 & 0.074 & $2.16^{*}$ \\
\hline PBC->ITU & 0.342 & 0.105 & $3.25^{*}$ \\
\hline SNI->ITU & -0.145 & 0.062 & $2.35^{\star}$ \\
\hline PEOU->PU & 0.415 & 0.104 & $3.97^{*}$ \\
\hline PEOU->A & 0.083 & 0.101 & 0.83 \\
\hline
\end{tabular}

*Signifikan pada 5\%

Sumber: Data primer diolah, 2014

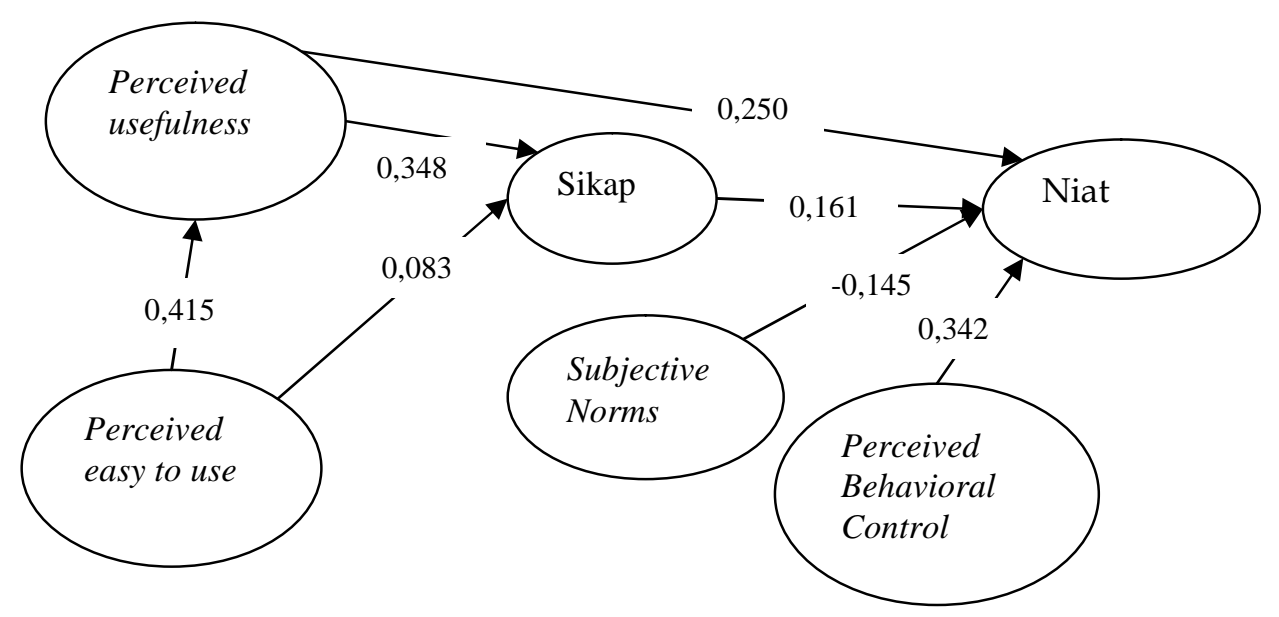

Gambar 2

Sumber: Data primer diolah, 2014.

Berdasarkan pengujian hipotesis dengan derajad signifikansi 5\% dengan nilai CR lebih dari atau sama dengan 1,96 maka hasil penelitian ini mengindikasikan bahwa hipotesis 2 dan hipotesis 5 tidak didukung. Hipotesis 2 yang menyatakan bahwa perceived easy to use berpengaruh terhadap sikap tidak didukung karena nilai CR tidak memenuhi cut-off sebesar lebih dari atau sama dengan 1,96 pada level signifikansi $5 \%$. 
Selanjutnya, hipotesis 5 yang menyatakan bahwa subjective norm berpengaruh positif terhadap niat, tidak didukung. Hasil menujukkan bahwa nilai CR sebesar 2,35 diatas 1,96 pada level signifikansi 5\%, namun nilai hubungan bersifat negatif yakni $-0,145$, sedangkan hipotesis lainnya didukung. Hipotesis 1 yang menyatakan bahwa perceived easy to use berpengaruh terhadap perceived usefulness, didukung. Nilai CR sebesar 3,97 diatas 2,56 pada level signifikansi sebesar 1\%. Hasil ini mengindikasi bahwa semakin mudah sistem online business dioperasikan maka semakin tinggi persepsi kemanfaatan sistem tersebut.

Hipotesis 3 yang menyebutkan bahwa perceived usefulness mempengaruhi sikap, didukung. Nilai CR sebesar 4,57 diatas cut off level 1\%, yakni 2,56. Hal ini menunjukkan bahwa bila individu merasakan manfaat dari sistem online business maka individu bersangkutan memiliki sikap yang positif terhadap adopsi online business.

Hipotesis berikutnya, yakni hipotesis 4 menyatakan bahwa sikap berpengaruh terhadap niat, didukung. Berdasarkan skor CR sebesar 2,16 diatas rule of thumb sebesar 1,96 pada level signifikansi 5\%. Hasil ini mengindikasikan bahwa sikap positif terhadap adopsi online business mempengaruhi niat untuk tetap menggunakan online business.

Hipotesis selanjutnya tentang pengaruh perceived behavioral control terhadap niat yang merupakan hipotesis 6 didukung. Skor CR sebesar 3,25 diatas 2,56 pada level signifikansi $1 \%$. Hasil ini membuktikan bahwa keyakinan (ability confident) dalam diri individu mempengaruhi niat adopsi.

Terakhir, hipotesis 7 yang menyatakan bahwa perceived usefulness berpengaruh terhadap niat, didukung. Besaran nilai $C R$ adalah 3,0 menunjukkan bahwa nilai tersebut diatas 2,56 untuk level signifikansi $1 \%$. Kemanfaatan yang diterima ketika menggunakan sistem online business memperkuat niat untuk tetap mengunakan sistem tersebut.

\section{Pengujian Mediasi}

Analisis mediasi dalam penelitian ini menggunakan Sobel test (Baron and Kenny, 1986). Rumus perhitungan Sobel test adalah

$z_{\text {_value }}=(\mathrm{a} \times \mathrm{b}) / \mathrm{SQRT}\left(\mathrm{b}^{2} \times \mathrm{SE}_{\mathrm{a}}{ }^{2}+\mathrm{a}^{2} \mathrm{x}\right.$ $\left.\mathrm{SE}_{b}{ }^{2}\right)$

dimana:

$\mathrm{a}=$ koefisien regresi standardized pengaruh variabel penjelas $X$ terhadap variabel mediasi $\mathrm{M} ; \mathrm{SE}_{\mathrm{a}}=$ standard error untuk koefisien a; $\mathrm{B}=$ koefisien regresi standardized pengaruh variabel mediasi terhadap variabel dependen $\mathrm{Y} ; \mathrm{SE}_{\mathrm{b}}=$ standard error untuk koefisien $b$.

Bila nilai $z$-value $\geq 1,96$ atau tingkat signifikansi statistik z (p-value) $\leq 0,05$ maka pengaruh tak langsung variabel independen terhadap variabel dependen melalui mediator (Preacher and Hayes, 2004).

Pengujian mediasi dilakukan antara variabel perceived usefulness terhadap sikap dan sikap terhadap niat. Oleh karena itu, variabel sikap dianalisis apakah sebagai variabel mediasi atau bukan variabel mediasi. Hasil perhitungan dengan Sobel test menunjukkan bahwa Z-value sebesar 1,965. Hasil ini mengindikasi bahwa variabel sikap memoderasi hubungan antara perceived usefulness dengan niat. Berdasarkan analisis GeSCA (lihat gambar 2) hubungan langsung maupun tidak langsung antara perceived usefulness dengan niat berpengaruh signifikan, oleh karena itu maka mediasinya bersifat parsial.

\section{Pembahasan}

Berdasarkan kekuatan prediksian antar hubungan variabel, niat adopsi online business dalam studi ini lebih kuat dipengaruhi oleh faktor intinsik yakni perceived behavioral control (nilai estimates: 0,342). Hasil ini mengindikasi bahwa kayakinan individu terhadap kemampuan dalam adopsi niat online business merupakan faktor dominan dalam keputusan adopsi.

Selain itu, perceived usefulness juga berperanan kuat dalam pembentukan niat adopsi (nilai estimates: 0,250). Kemanfaatan yang diterima dari online business menjadi- 
kan individu memiliki niat untuk mengadopsi online business. Semakin banyak manfaat yang dirasakan maka semakin tinggi niat adopsi, begitu pula sebaliknya. Sedangkan jalur sikap merupakan kekuatan berikutnya yang membentuk niat adopsi. Sikap positif terhadap aktifitas online business menciptakan niat adopsi online business tersebut. Lebih lanjut, sikap merupakan variabel yang memediasi secara parsial hubungan perceived usefulness dengan niat. Hal ini mengindikasi bahwa perubahan niat adopsi online business yang dipengaruhi oleh perceived usefulness sebagai fungsi dari variabel sikap (Baron and Kenny, 1986).

Hubungan antara subjective norm dengan niat tidak berpengaruh positif. Subjective norm dalam penelitian ini merujuk pada orang-arang terdekat, seperti keluarga, kerabat, dan teman. Subjective norm mewakili faktor eksternal indvidu dan tidak berdampak positif terhadap niat adopsi online business. Faktor utama penyebab adalah individu dalam penelitian ini merupakan personal yang pernah melakukan online business dan frekuensi transaksi cukup tinggi (lihat tabel 3). Kondisi ini berdampak pada rasa percaya diri yang tinggi untuk adopsi kembali online business, sehingga faktor eksternal menjadi tidak dominan.

Hasil penelitian ini menunjukkan bahwa TPB memiliki kekuatan prediksian yang bagus untuk setting adopsi online business bagi wirausaha. Namun perlu kehati-hatian dalam hubungan subjective norm terhadap niat, karena nilai hubungan bersifat negatif. Faktor utama terbentuknya hubungan negatif ini diprediksi karena setting penelitian ini berbeda dengan penelitian terdahulu. Setting studi ini focus pada niat ulang untuk adopsi online business. Individu yang telah mengadopsi sistem memiliki keyakinan diri yang tinggi sehingga faktor eksternal yakni subjective norm justru tidak signifikan. Oleh karena itu, pembentukan niat untuk adopsi online business dibentuk oleh sikap terhadap online business, dan perceived behavioral control. Hasil studi ini mendukung penelitian terdahulu yang dilakukan oleh (Fishbein and Ajzen, 1974; 1981; Ajzen, 1991; Ajzen and Fishbein, 1969).

Hasil yang relatif sama juga ditunjukkan oleh TAM. Secara keseluruhan TAM mampu memprediksi mengenai perilaku adopsi online business. Namun, pengujian lanjut perlu dilakukan untuk hubungan antara perceived easy to use terhadap sikap karena hubungan ini tidak terbukti. Fokus utama adopsi TAM berdasarkan hasil studi ini adalah perceived usefulness (kemanfaatan) menjadi faktor dominan dalam setting adopsi ulang online business dibandingkan perceived easy to use (kemudahan). Hasil akan berbeda diduga terjadi pada penelitian dengan setting yang belum mengadopsi online business.

\section{SIMPULAN}

\section{Simpulan}

Model penelitian dalam studi ini berfokus pada niat ulang adopsi online business pada setting mahasiswa yang berbisnis online. Hasil analisis menunjukkan bahwa niat ulang adopsi online business bertumpu pada keyakinan diri akan kemampuan menjalankan sistem online business. Lebih dari itu, faktor manfaat dari sistem yang diadopsi juga merupakan pertimbangan. Selain itu, sikap positif yang dibentuk dari persepsi manfaat yang dirasakan berpengaruh juga terhadap niat adopsi.

Hal yang berbeda terjadi pada persepsi kemudahan yang tidak berpengaruh terhadap sikap serta peranan orang-orang dekat juga tidak berdampak. Hal ini kuat diduga berkaitan dengan setting penelitian.

\section{Implikasi Manajerial}

Aplikasi hasil penelitian ini bagi pembentukan wirausaha muda berbasis teknologi informasi dan atau bagi pengembangan adopsi online business bertumpu pada pembentukan keyakinan akan kemampuan menjalankan sistem teknologi 
informasi. Keyakinan tersebut dibentuk terutama melalui motivasi intrinsik bahwa ketika yakin mengoperasikan sistem tersebut maka pasti berhasil (nilai estimates 0,601: lihat apendiks A) .

Faktor berikutnya adalah kemanfaatan sistem yang diadopsi, manfaat utama online business yang berpengaruh kuat terhadap adopsi sistem adalah kemudahan berinteraksi dengan konsumen (estimates 0,442: lihat apendiks B). Oleh karena itu, fokus utama pengembangan online business dengan memperkuat keyakinan bahwa sistem tersebut mampu menciptakan kemudahan kontak dengan konsumen dibandingkan dengan sistem konvensional

Terakhir, faktor sikap terhadap sistem online business. Prioritas aplikasi faktor sikap adalah dengan menciptakan penilaian positif terhadap online business (nilai estimates 0,289: lihat apendiks A). Selain itu juga dengan memperkuat persepsi bahwa adopsi sistem tersebut merupakan pilihan yang baik dan bijak dalam era teknologi informasi saat ini.

\section{Keterbatasan Penelitian}

Studi ini berfokus pada niat adopsi ulang online business pada kalangan mahasiswa. Oleh karena itu, perlu kehati-hatian untuk generalisasi model. Konteks antara niat adopsi ulang dengan niat adopsi bisa berbeda, sehingga penelitian lanjut dapat dilakukan pada setting niat adopsi bagi individu yang belum pernah melakukan online business.

\section{DAFTAR PUSTAKA}

Aaker, D. A., Kumar, V., and Day, G. S. 2000. Marketing Research (7th ed.). Singapore: John Wiley and Sons, Inc.

Ajzen, I. (1991). The Theory of Planned Behavior. Organizational Behavior and Human Decision Process 211(50): 179-211. Ajzen, I., and Fishbein, M. 1969. The Prediction of Behavioral Intention in a Choice Situation. Journal Of Experimental Social Psychology 5: 400-416.
Almahamid, S., Mcadams, A. C., Kalaldeh, T. A. L., and Eed, M. O. T. A. Z. A. 2010. The Relationship Between Perceived Usefulness, Perceived Ease Of Use, Perceived Information Quality, And Intention To Use E-Government. Journal of Theoretical and Applied Information Technology.

Baron, R. M., and Kenny, D. A. (1986). The Moderator-Mediator Variable Distinction in Social Psychological Research: Conceptual, Strategic, and Statistical Considerations. Journal of Personality and Social Psychology 51(6): 1173-1182.

Blanchard, C. M., Courneya, K. S., Rodgers, W. M., Fraser, S. N., Murray, T. C., Daub, B., and Black, B. (2003). Is the Theory of Planned Behavior a Useful Framework for Understanding Exercise Adherence During Phase II Cardiac Rehabilitation? Journal of Cardiopulmonary Rehabilitation 23: 29-39.

Chuttur, M. 2009. Overview of the Technology Acceptance Model: Origins, Developments and Future Directions 9: 9-37).

Cowen, J. B. 2009. The Influence of Perceived Usefulness, Perceived Ease of Use, and Subjective Norm on the Use of Computed Radiography Systems: A Pilot Study.

Crask, M., Fox, R. J., and Stout, R. G. 1995. Marketing Research: Principles and Applications. New Jersey: Prentice Hall.

Davis, F. D. 1989. Perceived Usefulness, Perceived Ease Of Use, And User Accep. MIS Quarterly (September): 319340.

Davis, F. D. 1993. User Acceptance of Information Technology: System Characteristics, User Perceptions, and Behavioral Impacts. Intl. J. Man-Machine Studies 38: 475-487.

Davis, F. D., Bagozzi, R. P., and Warshaw, P. R. 1989. User Acceptance Of Computer Technology: A Comparison Of Two Theoretical Models. Management Science 35(8): 982-1003.

Fishbein, M., and Ajzen, I. 1974. Attitude Toward Objects As Predictors of Single 
and Multiple Behavioral Criteria. Psychological Review 81(1): 59-74.

Fishbein, M., and Ajzen, I. 1981. Attitudes and Voting Behaviour: An Application of the Theory of Reasoned Action. Progress in Applied Social Psychology 1: 253-313.

Hwang, H., and Park, S. 2014. Generalized Structure Component Analysis. www. sem-gesca.org.

Preacher, K., and Hayes, A. 2004. Spss And Sas Procedures For Estimating Indirect Effects In Simple Mediation Models. Behavior Research Methods, Instruments, and Computers: A Journal of The Psychonomic Society, Inc 36(4): 717737.

Sekaran, U. 1992. Research Methods for Business: A Skill Building Approach (Second Edi.). Singapore: John Willey and Sons, Inc.

Shen Demei, Laffey James, Lin Yinmei, and H. X. 2006. Social Influence for Perceived Usefulness and Ease-of-Use of Course Delivery Systems Demei Shen, James Laffey, Yimei Lin, and Xinxin Huang University of Missouri, Columbia. Journal of Intercative Online Learning 5(3): 270-282.
Solimun. 2013. Technical Assistance: Generalized Structure Component Analysis.

Templeton, G. F., and Byrd, T. A. 2003. Determinants of the Relative Advantage of a Structured SDM During the Adoption Stage of Implementation. Information Technology and Management 4(4): 409-428.

Vallerand, R. J., Deshaies, P., Cuerrier, J.-P., Pelletier, L. G., and Mongeau, C. 1992. Ajzen and Fishbein's Theory of Reasoned Action as Applied to Moral Behavior: A Confirmatory Analysis. Journal of Personality and Social Psychology 62(1): 98-109.

Venkatesh, V. 2000. Determinants of Perceived Ease of Use: Integrating Control, Intrinsic Motivation, and Emotion into the Technology Acceptance Model. Information System Research 11(4): 342365.

Yusoff, Y. M., and Muhammad, Z. 2009. Individual Differences, Perceived Ease of Use, and Perceived Usefulness in the E-Library Usage. Computer and Information Science 2(1): 2-9. 


\section{Apendiks A}

Measurement Model

\begin{tabular}{|c|c|c|c|c|c|c|c|c|c|}
\hline \multirow[t]{2}{*}{ Variable } & \multicolumn{3}{|c|}{ Loading } & \multicolumn{3}{|c|}{ Weight } & \multicolumn{3}{|c|}{ SMC } \\
\hline & Estimate & SE & CR & Estimate & SE & $\mathbf{C R}$ & Estimate & SE & $\mathrm{CR}$ \\
\hline PU & \multicolumn{9}{|c|}{$\mathrm{AVE}=0.691, \mathrm{Alpha}=0.777$} \\
\hline PU3 & 0.804 & 0.055 & $14.54^{*}$ & 0.442 & 0.041 & $10.7^{*}$ & 0.646 & 0.085 & $7.61^{*}$ \\
\hline PU5 & 0.852 & 0.042 & $20.1^{*}$ & 0.420 & 0.046 & $9.1^{*}$ & 0.727 & 0.072 & $10.12^{*}$ \\
\hline PU6 & 0.838 & 0.032 & $26.2^{*}$ & 0.342 & 0.046 & $7.42^{*}$ & 0.701 & 0.053 & $13.27^{*}$ \\
\hline A & \multicolumn{9}{|c|}{$\mathrm{AVE}=0.817, \mathrm{Alpha}=0.925$} \\
\hline A1 & 0.875 & 0.033 & $26.82^{*}$ & 0.277 & 0.018 & $15.32^{*}$ & 0.765 & 0.057 & $13.42^{*}$ \\
\hline A2 & 0.924 & 0.019 & $49.88^{*}$ & 0.289 & 0.026 & $10.95^{*}$ & 0.853 & 0.034 & $25.12^{*}$ \\
\hline A3 & 0.891 & 0.026 & $34.72^{*}$ & 0.263 & 0.024 & $10.77^{*}$ & 0.794 & 0.046 & $17.44^{*}$ \\
\hline $\mathrm{A} 4$ & 0.925 & 0.018 & $52.0^{*}$ & 0.278 & 0.026 & $10.61^{*}$ & 0.856 & 0.033 & $26.23^{*}$ \\
\hline PBC & \multicolumn{9}{|c|}{$\mathrm{AVE}=0.740, \mathrm{Alpha}=0.645$} \\
\hline PBC6 & 0.870 & 0.037 & $23.3^{*}$ & 0.601 & 0.041 & $14.64^{*}$ & 0.758 & 0.065 & $11.72^{*}$ \\
\hline PBC7 & 0.850 & 0.038 & $22.51^{*}$ & 0.561 & 0.045 & $12.46^{*}$ & 0.722 & 0.064 & $11.22^{*}$ \\
\hline ITU & \multicolumn{9}{|c|}{ AVE $=0.711$, Alpha $=0.893$} \\
\hline ITU1 & 0.897 & 0.031 & $28.77^{*}$ & 0.258 & 0.026 & $9.95^{*}$ & 0.805 & 0.055 & $14.52^{*}$ \\
\hline ITU2 & 0.886 & 0.031 & $28.51^{*}$ & 0.276 & 0.022 & $12.32^{*}$ & 0.785 & 0.054 & $14.43^{*}$ \\
\hline ITU3 & 0.800 & 0.062 & $12.89^{*}$ & 0.214 & 0.027 & $7.88^{*}$ & 0.640 & 0.096 & $6.65^{*}$ \\
\hline ITU4 & 0.859 & 0.034 & $25.38^{*}$ & 0.230 & 0.021 & $10.7^{*}$ & 0.739 & 0.058 & $12.75^{\star}$ \\
\hline ITU5 & 0.766 & 0.067 & $11.37^{*}$ & 0.203 & 0.027 & $7.44^{*}$ & 0.587 & 0.103 & $5.71^{*}$ \\
\hline $\mathrm{SN}$ & \multicolumn{9}{|c|}{$\mathrm{AVE}=0.643, \mathrm{Alpha}=0.698$} \\
\hline SN2 & 0.566 & 0.141 & $4.02^{*}$ & 0.284 & 0.067 & $4.26^{*}$ & 0.321 & 0.120 & $2.67^{*}$ \\
\hline SN3 & 0.898 & 0.020 & $45.93^{*}$ & 0.455 & 0.026 & $17.33^{*}$ & 0.806 & 0.035 & $23.02^{*}$ \\
\hline SN4 & 0.895 & 0.017 & $51.6^{*}$ & 0.481 & 0.031 & $15.38^{*}$ & 0.802 & 0.031 & $25.78^{*}$ \\
\hline PEOU & \multicolumn{9}{|c|}{ AVE $=0.759$, Alpha $=0.919$} \\
\hline peou3 & 0.776 & 0.056 & $13.94^{*}$ & 0.223 & 0.019 & $11.72^{*}$ & 0.602 & 0.085 & $7.07^{*}$ \\
\hline peou4 & 0.894 & 0.025 & $35.81^{*}$ & 0.219 & 0.021 & $10.3^{*}$ & 0.800 & 0.045 & $17.97^{\star}$ \\
\hline peou5 & 0.919 & 0.017 & $54.86^{*}$ & 0.236 & 0.020 & $11.65^{*}$ & 0.845 & 0.031 & $27.57^{\star}$ \\
\hline peou6 & 0.920 & 0.017 & $55.43^{*}$ & 0.257 & 0.022 & $11.5^{*}$ & 0.846 & 0.030 & $27.98^{*}$ \\
\hline peou7 & 0.837 & 0.034 & $24.54^{*}$ & 0.212 & 0.015 & $14.56^{*}$ & 0.700 & 0.056 & $12.46^{*}$ \\
\hline
\end{tabular}

$\mathrm{CR}^{*}=$ significant at .05 level 
Measurement Model

\begin{tabular}{|c|c|c|c|c|c|c|c|c|c|}
\hline \multirow[t]{2}{*}{ Variable } & \multicolumn{3}{|c|}{ Loading } & \multicolumn{3}{|c|}{ Weight } & \multicolumn{3}{|c|}{ SMC } \\
\hline & Estimate & SE & CR & Estimate & SE & CR & Estimate & SE & CR \\
\hline PU & \multicolumn{9}{|c|}{ AVE $=0.691$, Alpha $=0.777$} \\
\hline PU3 & 0.804 & 0.055 & $14.54^{*}$ & 0.442 & 0.041 & $10.7^{*}$ & 0.646 & 0.085 & $7.61^{*}$ \\
\hline PU5 & 0.852 & 0.042 & $20.1^{*}$ & 0.420 & 0.046 & $9.1^{*}$ & 0.727 & 0.072 & $10.12^{*}$ \\
\hline PU6 & 0.838 & 0.032 & $26.2^{*}$ & 0.342 & 0.046 & $7.42^{*}$ & 0.701 & 0.053 & $13.27^{*}$ \\
\hline A & \multicolumn{9}{|c|}{$\mathrm{AVE}=0.817, \mathrm{Alpha}=0.925$} \\
\hline A1 & 0.875 & 0.033 & $26.82^{*}$ & 0.277 & 0.018 & $15.32^{*}$ & 0.765 & 0.057 & $13.42^{*}$ \\
\hline $\mathrm{A} 2$ & 0.924 & 0.019 & $49.88^{*}$ & 0.289 & 0.026 & $10.95^{*}$ & 0.853 & 0.034 & $25.12^{*}$ \\
\hline A3 & 0.891 & 0.026 & $34.72^{*}$ & 0.263 & 0.024 & $10.77^{*}$ & 0.794 & 0.046 & $17.44^{*}$ \\
\hline A4 & 0.925 & 0.018 & $52.0^{*}$ & 0.278 & 0.026 & $10.61^{*}$ & 0.856 & 0.033 & $26.23^{*}$ \\
\hline PBC & \multicolumn{9}{|c|}{$\mathrm{AVE}=0.740, \mathrm{Alpha}=0.645$} \\
\hline PBC6 & 0.870 & 0.037 & $23.3^{*}$ & 0.601 & 0.041 & $14.64^{*}$ & 0.758 & 0.065 & $11.72^{*}$ \\
\hline PBC7 & 0.850 & 0.038 & $22.51^{*}$ & 0.561 & 0.045 & $12.46^{*}$ & 0.722 & 0.064 & $11.22^{*}$ \\
\hline ITU & \multicolumn{9}{|c|}{$\mathrm{AVE}=0.711, \mathrm{Alpha}=0.893$} \\
\hline ITU1 & 0.897 & 0.031 & $28.77^{*}$ & 0.258 & 0.026 & $9.95^{*}$ & 0.805 & 0.055 & $14.52^{*}$ \\
\hline ITU2 & 0.886 & 0.031 & $28.51^{*}$ & 0.276 & 0.022 & $12.32^{*}$ & 0.785 & 0.054 & $14.43^{*}$ \\
\hline ITU3 & 0.800 & 0.062 & $12.89^{*}$ & 0.214 & 0.027 & $7.88^{*}$ & 0.640 & 0.096 & $6.65^{*}$ \\
\hline ITU4 & 0.859 & 0.034 & $25.38^{*}$ & 0.230 & 0.021 & $10.7^{*}$ & 0.739 & 0.058 & $12.75^{\star}$ \\
\hline ITU5 & 0.766 & 0.067 & $11.37^{*}$ & 0.203 & 0.027 & $7.44^{*}$ & 0.587 & 0.103 & $5.71^{*}$ \\
\hline $\mathrm{SN}$ & \multicolumn{9}{|c|}{$\mathrm{AVE}=0.643, \mathrm{Alpha}=0.698$} \\
\hline SN2 & 0.566 & 0.141 & $4.02^{*}$ & 0.284 & 0.067 & $4.26^{*}$ & 0.321 & 0.120 & $2.67^{*}$ \\
\hline SN3 & 0.898 & 0.020 & $45.93^{*}$ & 0.455 & 0.026 & $17.33^{*}$ & 0.806 & 0.035 & $23.02^{*}$ \\
\hline SN4 & 0.895 & 0.017 & $51.6^{*}$ & 0.481 & 0.031 & $15.38^{*}$ & 0.802 & 0.031 & $25.78^{*}$ \\
\hline PEOU & \multicolumn{9}{|c|}{ AVE $=0.759$, Alpha $=0.919$} \\
\hline peou3 & 0.776 & 0.056 & $13.94^{*}$ & 0.223 & 0.019 & $11.72^{*}$ & 0.602 & 0.085 & $7.07^{*}$ \\
\hline peou4 & 0.894 & 0.025 & $35.81^{*}$ & 0.219 & 0.021 & $10.3^{*}$ & 0.800 & 0.045 & $17.97^{*}$ \\
\hline peou5 & 0.919 & 0.017 & $54.86^{*}$ & 0.236 & 0.020 & $11.65^{*}$ & 0.845 & 0.031 & $27.57^{*}$ \\
\hline peou6 & 0.920 & 0.017 & $55.43^{*}$ & 0.257 & 0.022 & $11.5^{\star}$ & 0.846 & 0.030 & $27.98^{*}$ \\
\hline peou7 & 0.837 & 0.034 & $24.54^{*}$ & 0.212 & 0.015 & $14.56^{*}$ & 0.700 & 0.056 & $12.46^{*}$ \\
\hline
\end{tabular}

$\mathrm{CR}^{*}=$ significant at .05 level 


\section{Apendiks B}

Instrumen Penelitian

1. Perceived Easy to Use

a. Mudah dan fleksibel

b. Cepat memahami

c. Mudah menggunakan

d. Jelas dan mengerti

e. Secara keseluruhan mudah digunakan

2. Perceived Usefulness

a. Bisa berhubungan dengan konsumen

b. Mengetahui informasi seputar konsumen

c. Mengetahui keinginan konsumen
3. Sikap (Attitude)
a. Bijak
b. Positif
c. Bermanfaat
d. Baik

4. Perceived Behavioral Control
a. Mampu melakukan
b. Bila yakin maka bisa melakukan

5. Intention (Niat)
a. Akan menggunakan kembali
b. Menggunakan kembali untuk transaksi penjualan
c. Tertarik kembali
d. Menggunakan kembali karena ide yang bagus
e. Didukung oleh staf/karyawan.

\section{Apendiks C}

\begin{tabular}{|c|c|c|c|c|c|c|}
\hline \multicolumn{7}{|c|}{ Output Uji Validitas } \\
\hline & \multicolumn{6}{|c|}{ Factor } \\
\hline & 1 & 2 & 3 & 4 & 5 & 6 \\
\hline peou3 & .630 & & & & & \\
\hline peou4 & .863 & & & & & \\
\hline peou5 & .874 & & & & & \\
\hline peou6 & .912 & & & & & \\
\hline peou7 & .735 & & & & & \\
\hline pu5 & & & & & .760 & \\
\hline pu6 & & & & & .705 & \\
\hline a1 & & .770 & & & & \\
\hline $\mathrm{a} 2$ & & .885 & & & & \\
\hline a3 & & .832 & & & & \\
\hline $\mathrm{a} 4$ & & .899 & & & & \\
\hline pbc6 & & & & & & .441 \\
\hline pbc7 & & & & & & .767 \\
\hline itu1 & & & .796 & & & \\
\hline itu2 & & & .780 & & & \\
\hline itu3 & & & .696 & & & \\
\hline itu4 & & & .739 & & & \\
\hline itu5 & & & .639 & & & \\
\hline sni3 & & & & .764 & & \\
\hline sni2 & & & & .448 & & \\
\hline sni4 & & & & .903 & & \\
\hline
\end{tabular}




\begin{tabular}{|c|c|c|c|c|c|c|}
\hline \multicolumn{7}{|c|}{ Output Uji Validitas } \\
\hline & \multicolumn{6}{|c|}{ Factor } \\
\hline & 1 & 2 & 3 & 4 & 5 & 6 \\
\hline peou3 & .630 & & & & & \\
\hline peou4 & .863 & & & & & \\
\hline peou5 & .874 & & & & & \\
\hline peou6 & .912 & & & & & \\
\hline peou7 & .735 & & & & & \\
\hline pu5 & & & & & .760 & \\
\hline pu6 & & & & & .705 & \\
\hline a1 & & .770 & & & & \\
\hline $\mathrm{a} 2$ & & .885 & & & & \\
\hline a3 & & .832 & & & & \\
\hline $\mathrm{a} 4$ & & .899 & & & & \\
\hline pbc6 & & & & & & .441 \\
\hline pbc7 & & & & & & .767 \\
\hline itu1 & & & .796 & & & \\
\hline itu2 & & & .780 & & & \\
\hline itu3 & & & .696 & & & \\
\hline itu4 & & & .739 & & & \\
\hline itu5 & & & .639 & & & \\
\hline sni3 & & & & .764 & & \\
\hline sni2 & & & & .448 & & \\
\hline sni4 & & & & .903 & & \\
\hline $\begin{array}{l}\text { Peou:pe } \\
\text { behavior } \\
\text { Sumbe }\end{array}$ & $\begin{array}{l}\text { of } u \\
\text { tu:in } \\
\text { mer }\end{array}$ & $\begin{array}{l}\text { ived } u \\
\text { use (n } \\
014\end{array}$ & $\begin{array}{l}\text { a:atti } \\
\text { bjectio }\end{array}$ & o); $p b$ & & \\
\hline
\end{tabular}

\section{Apendiks D}

Output Uji Reliabilitas

\begin{tabular}{ll}
\hline \hline Variabel & Cronbach Alpha \\
\hline Perceived easy to use & 0,920 \\
Perceived usefulness & 0,780 \\
Attitude (sikap) & 0,926 \\
Subjective norms & 0,720 \\
Perceived behavioral control & 0,652 \\
Intention to use (niat) & 0,895 \\
\hline
\end{tabular}

Sumber: Data primer diolah, 2014 